\title{
BIOTECNOLOGIA E AGRICULTURA da ciência e tecnologia aos impactos da inovação
}

José Maria Ferreira Jardim da Silveira

Izaias de Carvalho Borges

Antonio Márcio Buainain

\begin{abstract}
Resumo: O texto mostra a evolução recente da biotecnologia agrícola, sua situação no Brasil atual, e faz um balanço de seus impactos econômicos e sociais. Chama atenção para o fato de esta tecnologia ter passado rapidamente do estágio de ciência para o de inovação, com impactos significativos na economia nacional. Palavras-chave: Biotecnologia agrícola. Impactos econômicos. Transgênicos.

Abstract: The paper show the recent agriculture biotechnology evolution, the brazilian situation and does a balance of the economics and socials impacts. The paper call attention to the fact of that technology to be quickly changing from the science's level to the innovation one, with significant impacts in the national economy.

Key words: Agricultural biotechnology. Economic impacts. Transgenic.
\end{abstract}

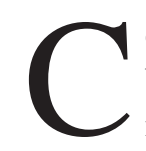
om a descoberta da tecnologia do DNA recombinante, a emergência da biotecnologia moderna nos anos 70 significou uma mudança radical no padrão tecnológico e organizacional de todos os setores que direta ou indiretamente estão ligados às "ciências da vida". A agricultura - e toda a cadeia produtiva da agroindústria - está entre os setores que mais impactos vem sofrendo com a descoberta dessa nova tecnologia.

Primeiramente, a biotecnologia moderna causou mudanças radicais na estrutura do mercado da indústria de fertilizantes e de sementes e, conseqüentemente, a indústria de insumos sofreu impactos. Depois, a partir de 1996, ela passou a ser introduzida na agricultura, por meio de sementes geneticamente modificadas. Finalmente, ela também começa a causar impacto na indústria de processamento, com a necessidade de rotulagem e rastreamento dos produtos derivados de cultivos geneticamente modificados.

Este artigo visa mostrar a evolução do crescimento da produção de cultivos geneticamente modificados e seus principais impactos econômicos, a partir de 1996. Na primeira parte faz uma breve descrição da biotecnologia agrícola moderna, suas principais aplicações, sua difusão, principais produtos e produtores. Em seguida, apresenta uma análise da biotecnologia no Brasil, país com grande peso no comércio mundial de commodities, com boa infraestrutura científica e tecnológica, mas com sérios obstáculos institucionais que o impedem de ter grande inserção no comércio mundial de cultivos geneticamente modificados. E, finalmente, analisa os principais estudos de impactos econômicos da difusão dos cultivos geneticamente modificados na agricultura, para os três grupos 
de commodities com maior proporção de variedades geneticamente modificadas: soja, algodão e milho. Os impactos são estudados sobre três variáveis: custo de produção, produtividade e inserção no mercado.

\section{BIOTECNOLOGIA E AGRICULTURA}

A biotecnologia pode ser definida como um conjunto de técnicas de manipulação de seres vivos ou parte destes para fins econômicos. Esse conceito amplo inclui técnicas que são utilizadas em grande escala na agricultura desde o início do século XX, como a cultura de tecidos, a fixação biológica de nitrogênio e o controle biológico de pragas. Mas o conceito inclui também técnicas modernas de modificação direta do DNA de uma planta ou de um organismo vivo qualquer, de forma a alterar precisamente as características desse organismo ou introduzir novas.

A técnica de transferência e modificação genética direta, conhecida como engenharia genética ou tecnologia do DNA recombinante, mais a genômica, ficaram conhecidas como "biotecnologia moderna", em contraposição à "biotecnologia tradicional ou clássica", que inclui as técnicas tradicionais, que manipulam seres vivos sem manipulação genética direta.

Portanto, o surgimento da biotecnologia moderna marca o início de um novo estágio para a agricultura e reserva um papel de destaque à genética molecular. Os avanços no campo da genética vegetal têm como efeito reduzir a dependência excessiva da agricultura das inovações mecânicas e químicas, que foram os pilares da revolução verde. Além do aumento da produtividade, a biotecnologia moderna pode contribuir para a redução dos custos de produção, para a produção de alimentos com melhor qualidade e para a o desenvolvimento de práticas menos agressivas ao meio ambiente.

Assim, a principal contribuição da biotecnologia moderna à agricultura é a possibilidade de criar novas espécies a partir da transferência de genes entre duas outras distintas. Essa transferência visa ao desenvolvimento de uma planta com um atributo de interesse econômico, como é o caso das plantas resistentes a vírus ou a pragas.

Os primeiros experimentos com cultivos geneticamente modificados (GM) foram feitos em 1986, nos Estados Unidos e na França. A primeira variedade comercializada de uma espécie vegetal produzida pela engenharia genética foi o "tomate FlavrSavr", desenvolvido pela empresa americana Calgene e comercializada a partir de 1994 (BORÉM; SANTOS, 2001).
Entre 1987 e 2000 foram realizados mais de 11.000 ensaios de campo em 45 países, com mais de 81 cultivos GM diferentes. As culturas mais freqüentemente testadas foram milho, tomate, soja, canola, batata e algodão, e as características genéticas introduzidas foram tolerância a herbicidas, resistência a insetos, qualidade do produto e resistência a vírus (BORÉM; SANTOS, 2001).

A utilização de cultivos GM para fins comerciais e em grande escala iniciou-se em 1996, nos Estados Unidos, com a introdução da soja RR. Como mostra o Gráfico 1, entre 1996 e 2003, a área plantada com cultivos GM cresceu de 2,8 milhões para 67,7 milhões de hectares.

GRÁFICO 1

Expansão Mundial da Produção de Cultivos GM 1996-03

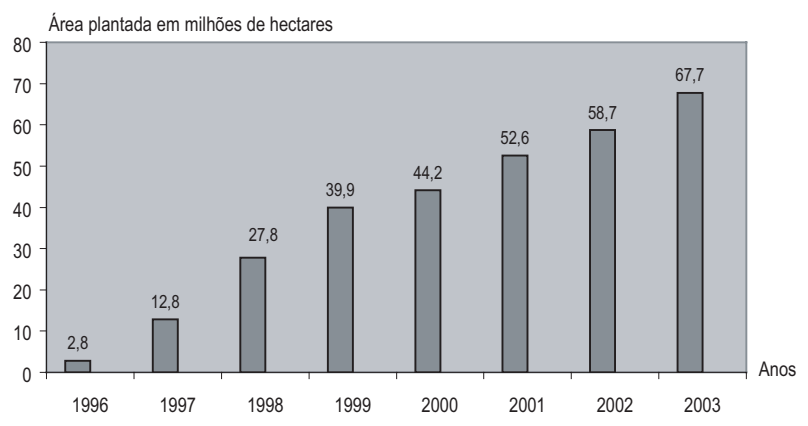

Fonte: James (2004)

Quanto aos atributos dos cultivos GM, há uma concentração nos cultivos tolerantes a herbicidas e nos resistentes a insetos. Em 2003, da área total com cultivos GM, $73 \%$ referiam-se a variedades tolerantes a herbicidas, $18 \%$ a variedades resistentes a insetos e $9 \%$ apresentavam as duas funções (JAMES, 2004).

Quanto aos produtos, a produção de cultivos GM está concentrada em quatro grupos de commodities de grande valor do comércio mundial: soja, milho, algodão e canola. Como mostra o Gráfico 2, a soja é o principal produto, pois responde por cerca de $60 \%$ da área mundial plantada com cultivos GM. Quanto à taxa de difusão (relação entre a produção de cultivos GM e os cultivos convencionais), a soja também se destaca dos demais, pois sua taxa de adoção em 2003 foi de cerca de 55\% em relação a produção mundial, como mostra o Gráfico 3. Nos Estados Unidos e na Argentina (primeiro e terceiro maiores produtores mundiais), essa taxa atinge $85 \%$ e $99 \%$, respectivamente. 


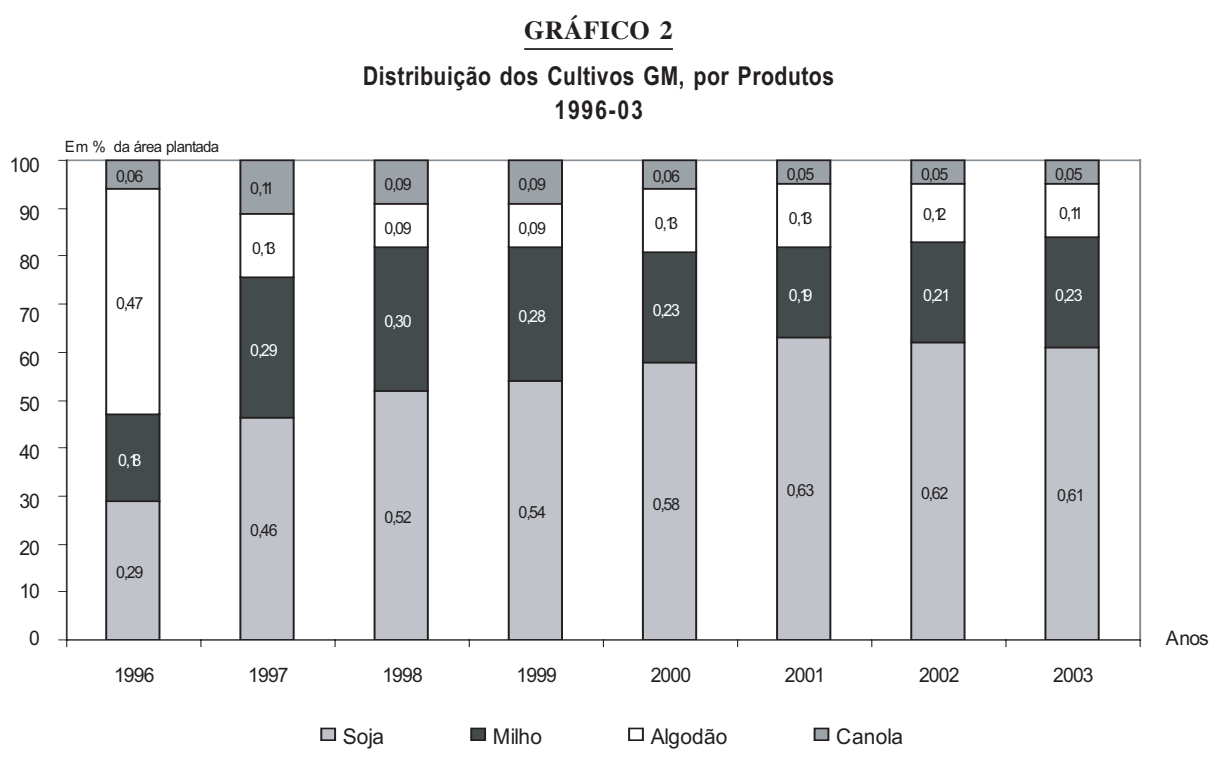

Fonte: Elaborado a partir de James (vários anos).

Como já foi mencionado antes, a difusão dos GM tem sido acelerada. Entre 1996 e 2003, a taxa de crescimento geométrico anual da área plantada com cultivos transgênicos foi de 46,42\%. Apesar da grande participação dos Estados Unidos, a Tabela 1 mostra que a difusão ocorreu também nos países em desenvolvimento, com destaque

\section{GRÁFICO 3 \\ Taxa de Adoção de Cultivos GM, por Produtos 2003}

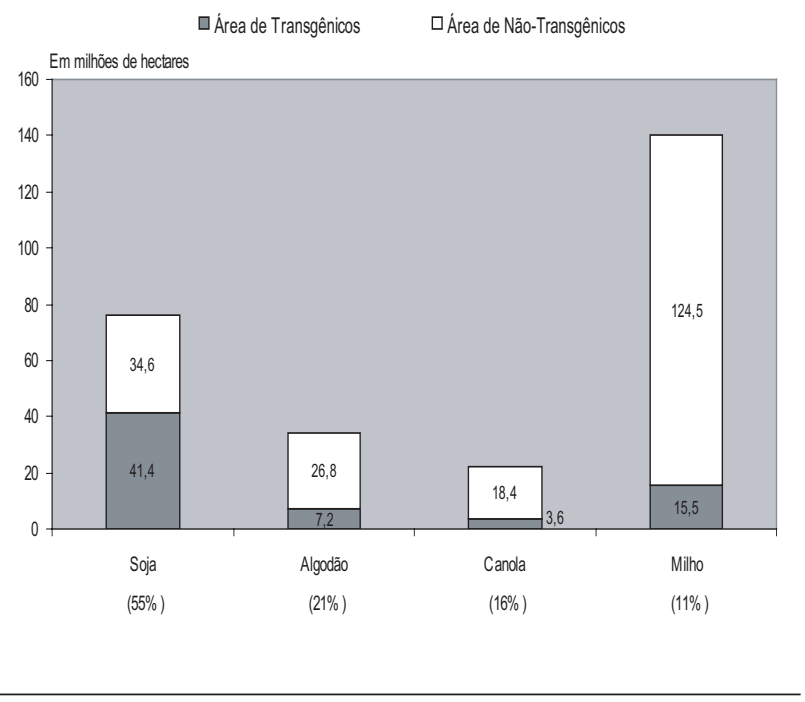

Fonte: James (2004) para a Argentina, que apresentou no mesmo período uma taxa de crescimento geométrico anual de $80 \%$.

Atualmente, os cultivos GM estão presentes em 18 países, os quais têm grande peso na economia regional e mundial. Os dez principais produtores de cultivos GM em 2003 tinham população de aproximadamente 3 bilhões de pessoas e PIB de US\$ 13 trilhões, quase a metade dos US\$ 30 trilhões do PIB mundial. Afora os Estados Unidos, estão entre os países produtores de cultivos GM: os três países mais populosos da Ásia (China, Índia e Indonésia) as três maiores economias da América Latina (Brasil, México e Argentina) e a principal economia africana (África do Sul).

Além do peso nas economias regionais, os países produtores de cultivos GM destacam-se também no comércio mundial de commodities. Como mostra a Tabela 2, os maiores produtores mundiais de soja, milho e algodão já adotaram cultivos GM.

A dimensão da difusão geográfica dos cultivos GM fica mais evidente quando são analisados os principais produtos disponíveis e aprovados para comercialização. ${ }^{1}$ Como a produção de soja, milho e algodão é concentrada em poucos países, é natural que a quantidade de países que produzem as variedades GM não seja muito maior. A soja, por exemplo, tem $93 \%$ da produção mundial cultivada em apenas cinco países. No caso do milho e do algodão, a concentração é um pouco menor, mas ainda assim é muito elevada: os cinco maiores produtores representam 
TABELA 1

Expansão da Área Plantada com Cultivos Transgênicos 1996-03

\begin{tabular}{|c|c|c|c|c|c|c|c|c|c|}
\hline \multirow{2}{*}{$\begin{array}{l}\text { Áreas com } \\
\text { Cultivos Transgênicos }\end{array}$} & \multicolumn{8}{|c|}{ Em milhões de hectares } & \multirow{2}{*}{$\begin{array}{c}\text { Taxa de Crescimento } \\
\text { Geométrico Anual } \\
(\%)\end{array}$} \\
\hline & 1996 & 1997 & 1998 & 1999 & 2000 & 2001 & 2002 & 2003 & \\
\hline Total & 2,8 & 12,8 & 27,8 & 39,9 & 44,2 & 52,6 & 58,7 & 67,7 & 46,4 \\
\hline Países Desenvolvidos & 1,6 & 9,5 & 23,4 & 32,8 & 33,5 & 39,1 & 42,7 & 47,3 & 47,7 \\
\hline Estados Unidos & 1,5 & 8,1 & 20,5 & 28,7 & 30,3 & 35,7 & 39 & 42,8 & 48,7 \\
\hline Países em Desenvolvimento & 1,2 & 3,3 & 4,4 & 7,1 & 10,7 & 13,5 & 16 & 20,4 & 45,5 \\
\hline Argentina & 0,1 & 1,4 & 4,3 & 6,7 & 10 & 11,8 & 13,5 & 13,9 & 80,0 \\
\hline
\end{tabular}

Fonte: Elaborado a partir de James (vários anos).

TABELA 2

Participação na Produção Total dos Cinco Principais Produtores Mundiais de Soja, Milho e Algodão

Países Selecionados - 2003

\begin{tabular}{lcc}
\hline Produtos / Países & Participação na & Adoção de Cultivos \\
& Produção Mundial (\%) & GM \\
\hline
\end{tabular}

Soja (em grãos)

Total

Estados Unidos

Brasil

Argentina

China

Índia

Milho

Total

Estados Unidos

China

Brasil

México

Argentina
93,0

35,0

27,0

18,0

9,0

4, 0

71,0

40,0

18,0

7,0

3,0

2,0

Algodão (em plumas)

\begin{tabular}{lll} 
Total & 71,0 & \\
China & 26,0 & $\operatorname{Sim}(58 \%)$ \\
Estados Unidos & 20,0 & $\operatorname{Sim}(37 \%)$ \\
Índia & 12,0 & $\operatorname{Sim}(1)$ \\
Paquistão & 9,0 & $\operatorname{Sim}(1)$ \\
Brasil & 4,0 & Não \\
\hline
\end{tabular}

Fonte: FNP-Agrianual (2004) e James (2004).

(1) Sem informação exata sobre a taxa de adoção.
$71 \%$ da produção mundial. Assim, o importante é salientar que, como mostra a Tabela 2 , dentre os maiores produtores mundiais dessas commodities, todos já produzem ou fazem experimentos de campo com cultivos GM.

A existência de restrições ao comércio de produtos GM em diversos países, especialmente na União Européia, não impediu seu vigoroso crescimento no mercado mundial. Entre 2002 e 2003, o valor comercializado com GM aumentou de US $\$ 4$ bilhões para algo estimado entre US $\$ 4,5$ bilhões e US $\$ 4,75$ bilhões. Em 2002, a participação mundial desse tipo de cultivo já era de 15\% dos US\$ 31 bilhões do mercado global de proteção de plantas e 13\% dos US $\$ 30$ bilhões do mercado de sementes. Entretanto, esse valor de mercado baseia-se apenas no preço das sementes acrescido das taxas de tecnologias aplicáveis (JAMES, 2004).

Se for considerado também o volume de comércio das três principais commodities com cultivos GM, o valor do mercado mundial é bem maior do que os US $\$ 4,5$ bilhões. A Tabela 3 apresenta um valor subestimado do volume de produção e de exportação mundial de cultivos GM em 2003. Esses valores estão subestimados porque não incluem a produção de canola e porque não é possível mensurar corretamente a produção em países como o Brasil devido à vasta produção clandestina.

Tomando como base os dados sobre as taxas de adoção apresentados por James (2004) estima-se que a produção total de cultivos GM dos três principais produtos foi de aproximadamente US\$ 30 bilhões em 2003 (Tabela 3). Já as exportações de cultivos GM de soja, algodão e milho em 2003, foi de aproximadamente US\$ 8,3 bilhões. A soja é o principal produto GM em termos de volume de exportações, representando $90 \%$ das exportações de cultivos GM em 2003. 
TABELA 3

Volume Estimado da Produção e da Exportação Mundial de Cultivos GM, por Produtos 2003

\begin{tabular}{|c|c|c|c|c|}
\hline $\begin{array}{l}\text { Volume da Produção } \\
\text { e Exportação }\end{array}$ & Soja & Algodão & Milho & $\begin{array}{c}\text { Produção } \\
\text { Total }\end{array}$ \\
\hline \multicolumn{5}{|l|}{ Produção Total } \\
\hline Em milhões de toneladas & 196 & 19 & 599 & 814 \\
\hline Em milhões de US\$ (1) & 41.885 & 890 & 57.264 & 100.039 \\
\hline \multicolumn{5}{|l|}{ Taxa de Adoção } \\
\hline de Transgênicos (\%) & 55,0 & 21,0 & 11,0 & \\
\hline \multicolumn{5}{|c|}{ Produção de Transgênicos } \\
\hline Em milhões de toneladas & 108 & 4 & 66 & 178 \\
\hline Em milhões de US\$ (1) & 23.037 & 187 & 6.299 & 29.523 \\
\hline \multicolumn{5}{|l|}{ Exportação } \\
\hline Em milhões de toneladas & 63 & 6,6 & 76 & 146 \\
\hline Em milhões de US\$ (1) & 13.463 & 309 & 7.265 & 21.037 \\
\hline \multicolumn{5}{|l|}{ Taxa de Adoção } \\
\hline de Transgênicos (\%) & 55,0 & 21,0 & 11,0 & \\
\hline \multicolumn{5}{|c|}{ Exportação de Transgênicos } \\
\hline Em milhões de toneladas & 35 & 1 & 8 & 44 \\
\hline Em milhões de US\$ (1) & 7.405 & 65 & 799 & 8.269 \\
\hline
\end{tabular}

Fonte: James (2004); FNP (2004).

(1) Calculado com base no preço de primeira entrega em Chicago.

\section{BIOTECNOLOGIA AGRÍCOLA NO BRASIL}

O Brasil é um país com grande potencial para o desenvolvimento da biotecnologia agrícola. Em primeiro lugar, é um país detentor de grande diversidade biológica e o mais rico em plantas, animais e microorganismos, com cerca de $20 \%$ do total existente. No caso de plantas superiores, o Brasil possui cerca de 55 mil espécies, o equivalente a $21 \%$ do total classificado em todo o mundo. Essa elevada concentração de biodiversidade mostra que existe um elevado número de genes tropicais e de genomas funcionais (VALOIS, 2001).

Em segundo lugar, dentre os países em desenvolvimento, o Brasil é considerado um Super NARS. Ou seja, é um país que possui um forte sistema nacional de pesquisa agrícola (TRAXLER, 2000). O Brasil é o único país tropical considerado um grande player no cenário agrícola mundial. Essa posição foi conquistada com muitos anos de pes- quisa científica voltada para um melhor aproveitamento das suas vantagens naturais: clima tropical e subtropical, cerrados (que permitem rápida expansão da área cultivada e aumento rápido da produtividade) e germoplasma selecionado e adaptado de grande variabilidade (obrigação frente à grande variabilidade ambiental). A pesquisa científica contribuiu não apenas para o aumento da produtividade, mas também para a melhora na qualidade dos produtos e para o aumento da diversificação da produção. A produção de soja na região Centro-Oeste e a de frutas na região Nordeste são exemplos da contribuição da pesquisa para a diversificação.

No caso da biotecnologia, o Brasil possui uma ampla rede de pesquisa, que tem a liderança do setor público, mas conta também com a participação de empresas privadas. Nas pesquisas genômicas, por exemplo, diversas etapas foram realizadas com a ajuda do setor privado.

Atualmente existem no Brasil diversos grupos em instituições públicas e universidades que estão desenvolvendo pesquisas com transgenia e genômica. Em 2000 havia 6.616 pesquisadores trabalhando com biotecnologia no país, distribuídos em 1.718 grupos e 3.814 linhas de pesquisas. As ciências agrárias lideravam os grupos, com 1.075 linhas de pesquisa. Grande parte dessa pesquisa estava concentrada em instituições públicas, mas, nos últimos anos, vem crescendo a participação das empresas privadas (SALLES FILHO, 2000).

Como mostra o Quadro 1, as pesquisas com transgenia no país têm a liderança da Empresa Brasileira de Pesquisa Agropecuária - Embrapa e de algumas universidades públicas. As pesquisas são direcionadas não apenas ao desenvolvimento de transgênicos com "propriedades agronômicas" (como resistência a pragas e tolerância a agrotóxicos), mas também com modificações na qualidade de produto, como é o caso da pesquisa para o desenvolvimento de um eucalipto com maior produção de celulose.

Outra área de destaque no Brasil é a da genômica. As pesquisas genômicas tiveram início em maio de 1997, com a iniciativa da Fundação de Amparo a Pesquisa do Estado de São Paulo - Fapesp em organizar a Rede ONSA (do inglês, Organização para o Seqüenciamento e Análise de Nucleotídeos), que é um instituto virtual de genômica formado inicialmente por 30 laboratórios de diversas instituições de pesquisa do Estado de São Paulo.

Além da Fapesp, o Ministério da Ciência e Tecnologia (MCT) e o Conselho Nacional de Pesquisa - CNPq estão financiando diversos projetos genomas no país. Em dezembro de 2000, eles lançaram o Projeto Genoma Brasilei- 
QUADRO 1

Pesquisas da Embrapa para o Desenvolvimento de Plantas Geneticamente Modificadas

\begin{tabular}{ll}
\hline Produtos & \\
\hline - Plantas que produzem hormônios & Instituição \\
- Mamão resistente ao vírus da manda anelar & Embrapa/Unicamp \\
- Feijão tolerante ao vírus do mosaico dourado & Embrapa \\
- Soja tolerante à herbicida & Embrapa \\
- Milho com alto teor de metionina & Embrapa \\
- Milho e Sorgo resistente à alumínio & Embrapa \\
- Batata resistente a vírus & Embrapa \\
- Arroz resistente a insetos & Universidade Federal do Rio de Janeiro \\
- Laranja resistente a vírus & Allelyx \\
- Maracujá resistente a doenças & Escola Superior de Agricultura Luiz de Queiroz - Esalq \\
- Eucalipto com maior produção de celulose & Escola Superior de Agricultura Luiz de Queiroz - Esalq
\end{tabular}

Fonte: Embrapa (2004); CIB (2004).

ro com a participação de 25 laboratórios de biologia molecular, distribuídos em todas as regiões geográficas do país (DAL POZ et al., 2004).

Há financiamento para diversos estudos genômicos no campo da saúde humana, ${ }^{2}$ mas grande parte deles está voltada para a resolução de problemas da agricultura. O Quadro 2 mostra, de forma resumida, os principais estudos genômicos de plantas e de outros organismos de interesse para agricultura desenvolvidos nos últimos anos. Afora esses, iniciou-se em 2002, com financiamento da Fapesp, o estudo do genoma funcional do boi, que poderá ter grande impacto na pecuária brasileira.

Além do setor público, a rede de pesquisa e inovação no Brasil conta com a participação ativa do setor privado. Um estudo realizado em 2001 pela Fundação Biominas, com base em dados da Base de Dados Tropicais (BDT) e da Associação Brasileira de Empresas de Biotecnologia (Abrabi), identificou a existência de 304 empresas de biotecnologia no país, distribuídas em 10 segmentos de mercado, dentre as quais, 37 atuam em agronegócios (JUDICE, 2004).

Uma parte considerável das empresas de biotecnologia no mercado de agronegócios produz e comercializa sementes melhoradas e conta com a participação das grandes empresas multinacionais, como Monsanto e Dupont. Mas também existem empresas que atuam em outros segmentos, como a produção de mudas e matrizes e a produção de inoculantes e de controle biológico (FONSECA et al., 2004).

Entretanto, apesar de existir uma forte rede de pesquisas e desenvolvimento e de o país ser um grande produtor e exportador agrícola, a difusão de organismos geneticamente modificados na agricultura é muito inferior à realizada nos outros competidores no comércio internacional, como os Estados Unidos e Argentina. Em 2003, a produção de transgênicos no Brasil representava apenas $4 \%$ da produção mundial. Além disso, a soja RR era o único produto transgênico produzido no país, embora este também fosse produtor de milho e algodão (JAMES, 2004).

A dificuldade para criar um quadro regulatório estável e coerente nos últimos oito anos foi a principal causa para o atraso do Brasil em relação aos seus concorrentes. Apesar do Decreto no 1.752, de 20 de dezembro de 1995, que regulamentou a Lei de Biossegurança e conferiu a CTNBio o poder de emitir pareceres conclusivos, uma ação judicial movida pelo Instituto Brasileiro de Defesa do Consumidor (Idec) e pelo Greenpeace impede a produção e a comercialização desses produtos desde 1998.

Entretanto, essa situação não impediu a difusão clandestina da soja transgênica no país, principalmente no estado do Rio Grande do Sul. O grande volume de colheita transgênica nesse estado forçou o governo federal a emitir, em 2003, uma medida provisória que liberava essa colheita.

Em 2004, a área cultivada com soja transgênica no Brasil foi de 5.610 milhões de hectares - o equivalente a quase um terço da área cultivada com soja convencional. Mas, considerando-se as vantagens da soja transgênica para os produtores e um possível avanço no quadro regulatório da biossegurança, as projeções são de aumento da participação da soja transgênica na produção brasileira.

Assim, a aprovação e sanção recente de uma Lei de Biossegurança criaram grandes expectativas em diversos setores envolvidos com alguma atividade no campo da biotecnologia: instituições públicas de pesquisa, universidades, empresas privadas nacionais e estrangeiras e fundos de investimento ao capital de risco. 
QUADRO 2

Estudos Genômicos no Brasil: Plantas, Fitopatógenos e Microorganismos de Interesse para a Agricultura

\begin{tabular}{ll}
\hline Projeto & \\
\hline - Xylella fastidiosa & Instituição \\
- Genoma Cana & Fapesp e Fundecitrus \\
- Programa Genoma do Estado do Paraná & Universidade Federal do Paraná/MCT/CNPq \\
- Programa Genoma do Estado do Rio de Janeiro & Universidade Federal do Rio de Janeiro/MCT/CNPq \\
- Rede Genômica no Estado da Bahia & Universidade Estadual de Campinas/MCT/CNPq \\
- Genoma da Laranja & Alellyx \\
- Genoma Xanthomonas & Fapesp \\
- Projeto Forests & Fapesp \\
- Genoma da Banana & Embrapa \\
- Geifsonia xyli & Fapesp \\
\hline
\end{tabular}

Fonte: Dal Poz et al. (2004).

\section{OS IMPACTOS ECONÔMICOS DOS CULTIVOS GENETICAMENTEMODIFICADOS}

Neste item será feita uma análise dos impactos econômicos da difusão da biotecnologia moderna na agricultura. A principal questão é saber se o uso da nova tecnologia aumenta a competitividade do produtor agrícola perante seus concorrentes. Para isso, serão analisados os impactos sobre o nível de custos de produção e de produtividade e a inserção dos cultivos GM no mercado.

A literatura sobre os impactos dos cultivos GM ainda é muito escassa. Grande parte dos estudos está concentrada nos impactos sobre custos e produtividade na produção de soja RR nos Estados Unidos e na Argentina, de algodão Bt na China e de milho Bt na Espanha e nos Estados Unidos.

\section{Impactos Econômicos Diretos: Custos e Produtividade}

A seguir, serão mostrados os principais impactos econômicos dos cultivos GM comercializados atualmente no mundo, segundo seus atributos: tolerância a herbicida e resistência a insetos.

Cultivos Tolerantes a Herbicidas - A soja RR é o principal produto do grupo dos cultivos GM tolerantes a herbicidas. Foi desenvolvida com a introdução do gene da bactéria Agrobacterium tumefaciens em seu DNA. Essa bactéria vive naturalmente no solo e é resistente ao glifosato - um herbicida de amplo espectro. Assim, a soja que recebe o gene dessa bactéria também torna-se resistente.
Segundo Bonny (2003), uma das principais vantagens da soja RR é a simplificação do trabalho de remover as ervas daninhas. Na soja convencional, os produtores precisam fazer diversas aplicações de herbicidas e mesmo assim muitas são de difícil controle. Assim, a soja RR facilita a gerência da erva daninha, simplifica o uso de herbicidas e reduz o risco e falta de controle sobre as pragas.

Além dessas vantagens, alguns autores também relatam impactos significativos sobre os custos de produção e produtividade. Segundo Hubbell e Welsh (1998), em 1996, nos Estados Unidos, a adoção da soja RR provocou uma redução de custos por hectare entre US\$ 17 e US\$ 30 no país como um todo. Moschini et al. (2000) estimou um ganho de custo de US\$20 por hectare. Em alguns estados, a diferença de custos entre a soja RR e a tradicional foi insignificante, como é o caso do Estado de Iowa (DUFFY, 2001). Em outros, a diferença de custos chegou a US\$ 40 ou mais (GIANESSI et al., 2002).

$\mathrm{Na}$ Argentina, os principais benefícios da soja RR para os produtores foram a redução dos custos de produção e a expansão da área plantada. De acordo com Trigo et al. (2003), a grande vantagem da soja RR foi a redução do custo variável, principalmente a redução dos gastos com herbicidas, máquinas e mão-de-obra. A redução dos custos desses três fatores foi mais que suficiente para compensar o aumento do custo com sementes.

Segundo Trigo et al. (2003), a soja transgênica não só causou impacto sobre os custos de produção, como também sobre o rendimento e os volumes de produção e comércio. Na Argentina, a soja RR contribuiu para o aumento da área com plantio direto e, conseqüentemente, para o aumento da área plantada. Entre 1996 e 2003, a área plantada com soja aumentou de 6,4 milhões para 12,8 milhões de 
hectares. Como essa expansão ocorreu através da combinação de plantio direto-soja de segunda, não houve a substituição de outros cultivos (TRIGO et al., 2003).

A introdução da soja GM na Argentina apresentou ainda dois outros resultados: aumento do rendimento e das exportações. Entre 1996 e 2003, o rendimento na produção de soja na Argentina aumentou cerca de uma tonelada por hectare: passou de $1.720 \mathrm{~kg} / \mathrm{ha}$ para $2.764 \mathrm{~kg} / \mathrm{ha}$. Já a exportação, somando a de grãos e a de derivados (farelos e óleo), mais do que triplicou em sete anos (TRIGO et al., 2003).

$\mathrm{O}$ aumento da produção de soja na Argentina nesse período objetivou essencialmente o mercado externo. Em 2003, 97\% da produção de farelo e 99,5\% de óleo foram exportadas. No mesmo ano, esses dois produtos argentinos representaram, respectivamente, $41,3 \%$ e $47,9 \%$ das exportações mundiais (FNP, 2004).

Cultivos Resistentes a Insetos - A principal vantagem econômica dos cultivos GM resistentes a insetos é a redução dos gastos com inseticidas, implicando uma redução no custo variável de produção. Assim, as vantagens de utilizar a variedade GM dependerão da participação dos gastos com inseticidas na planilha de custos do produtor. Quanto maior for a incidência de pragas, maiores serão as vantagens da variedade GM.

Os dois principais produtos resistentes a insetos comercializados atualmente são o algodão Bt e o milho Bt. $\mathrm{O}$ algodão Bt contém um gene da bactéria Bacillus thuringiensis $(\mathrm{Bt})$, resistentes a pragas de insetos e foi cultivado pela primeira vez em 1996, na Austrália, México e nos Estados Unidos. Posteriormente foi introduzido comercialmente em outros seis países: Argentina, China, Colômbia, Índia, Indonésia e África do Sul (JAMES, 2004).

$\mathrm{O}$ algodão Bt é muito eficiente para combater pragas de lagartas, como a rosada do algodoeiro (Pectinophora gossypiella), e a cápsula do algodoeiro (Helicoverpa zea) e é parcialmente eficiente contra a lagarta do broto do tabaco (Heliothis virescens) e a lagarta negra (Spodoptera frugiperda). Essas pragas prejudicam a produção em diversas zonas produtoras de algodão, mas existem outras que não são combatidas pelo Bt e que continuam necessitando do uso de praguicidas químicos. Como conseqüência, os efeitos do algodão Bt nas diversas regiões produtoras serão diferentes, dependendo da intensidade de incidências de pragas suscetíveis ao Bt.

A produção de algodão convencional depende decisivamente dos inseticidas químicos para combater os insetos. Segundo o Relatório da FAO (Food and Agriculture Organization of the United Nations), a produção de algodão consome cerca de $25 \%$ de todos os praguicidas agrícolas utilizados em todo o mundo. Na China - que é o maior produtor de algodão do mundo - até 1998, cerca de $20 \%$ do custo total da produção de algodão era com inseticidas (HUANG et al., 2003).

Os resultados mais evidentes do uso do algodão Bt são a redução dos custos, o aumento do rendimento e da produtividade. A Tabela 4 apresenta um resumo de estudos dos impactos do algodão Bt nos diversos países produtores. Os dados mostram que em todos os países houve redução de custos e incrementos de produtividade, com o seguinte padrão geral: os ganhos de produtividade foram significativos na Ásia (China e Índia) e na África do Sul,

TABELA 4

Impactos da Adoção de Algodão Bt nas Principais Regiões Produtoras 1999-2001

\begin{tabular}{|c|c|c|c|c|c|c|c|}
\hline \multirow{2}{*}{ Países/Regiões } & \multirow{2}{*}{$\begin{array}{c}\text { Participação } \\
\text { na Produção } \\
\text { Mundial } \\
(\text { Em \%) }\end{array}$} & \multicolumn{4}{|c|}{$\begin{array}{l}\text { Variaçães no Custo dos Insumos e do Rendimetno após a } \\
\text { Introdução do Algodão Bt (Em \%) }\end{array}$} & \multirow{2}{*}{$\begin{array}{c}\text { Taxa de } \\
\text { Adoção do } \\
\text { Algodão BT } \\
(\text { Em \%) }\end{array}$} & \multirow{2}{*}{$\begin{array}{l}\text { Variação na } \\
\text { Produtividade } \\
\text { Induzida pelo } \\
\text { Algodão } B\end{array}$} \\
\hline & & Inseticidas & Sementes & Mão-de-Obra & Rendimento & & \\
\hline Austrália & 4,3 & -80 & 80 & -2 & 0 & 25 & 3,24 \\
\hline China & 15,1 & -82 & 220 & $-9,5$ & 15 & 58 & 7,65 \\
\hline Índia & 16 & -49 & 386 & 34 & 58 & 25 & 10,2 \\
\hline EUA & 15,5 & -80 & 80 & -2 & 0 & 37 & 1,74 \\
\hline Canadá & 2,7 & -77 & 166 & -15 & 8,5 & 30 & 1,49 \\
\hline América Latina & 7,5 & -46 & 166 & 17 & 33 & 5 & 1,85 \\
\hline África do Sul & 1,3 & -25 & 110 & -8 & 18 & 40 & 8,21 \\
\hline África Central e Ocidental & 5,1 & -25 & 110 & -8 & 18 & 25 & 5,29 \\
\hline
\end{tabular}

Fonte: Elbehri; Macdonald (2005). 
mas foram pequenos nos Estados Unidos. Em compensação, a redução dos custos com inseticidas foi maior nesse país do que nos demais, com exceção da China. A Índia, que teve o maior aumento da produtividade, também apresentou maior aumento no custo com sementes.

As diferenças entre os impactos sobre os custos, mostradas na Tabela 4, explicam-se pelas diferenças climáticas, que afetam a incidência de pragas. Nas regiões onde o uso de inseticidas é muito intenso, o algodão Bt é mais competitivo do que o tradicional - mesmo com o aumento do custo da semente - pois a redução nos gastos com inseticidas é muito grande (considerando que a participação destes na planilha de custos é muito maior do que a participação da semente). Nos Estados Unidos, por exemplo, em apenas dois estados - Louisiana e Tennessee não houve aumento da produtividade com a utilização do algodão Bt. As diferenças regionais dos impactos estão relacionadas com a incidência de pragas. Eles são mais elevados nas regiões que têm maior incidência e que, portanto, utilizam grandes quantidades de inseticidas (MARRA et al., 2002).

O país que mais se beneficiou da queda no custo de produção foi a China. Entre 1999 e 2001, os gastos com inseticidas tiveram uma redução de $80 \%$. Um estudo realizado com 482 unidades produtivas de algodão - 337 produtores de algodão GM e 45 de algodão convencional - mostrou que, em média, o número de aplicações de inseticidas por hectare nas unidades que produzem algodão Bt é um terço das demais. A quantidade (kg/ha) e o custo (em US\$/ha) nas unidades produtoras de Bt é um sexto do das demais unidades (HUANG et al., 2003).

Além da redução dos gastos com inseticidas, o algodão Bt trouxe outras vantagens para os produtores. Normalmente a utilização de inseticidas químicos está relacionada com um inconveniente: as pragas desenvolvem resistências, o que, na ausência de outro produto eficiente, inviabiliza a produção. Mas, no caso da tecnologia Bt, a ação contra as pragas estão sempre presentes na planta. Considerando que os agricultores aplicam os inseticidas químicos somente depois de detectar a presença das pragas e seus estragos, a tecnologia Bt impede a perda parcial da lavoura. Além disso, a eficiência dos inseticidas químicos, ao contrário do Bt, depende também das condições metereológicas, já que a chuva pode impedir a ação dos produtos jogados sobre as plantas. Por fim, o algodão Bt oferece aos agricultores mais certeza de combate às pragas, já que é eficiente contra os insetos que têm criado resistência aos inseticidas químicos disponíveis (HUANG et al., 2003).
Os estudos com o milho Bt mostram resultados muito parecidos com os do algodão. A utilização do milho Bt também causou impactos positivos sobre a produtividade, sobre o lucro e sobre os custos de produção. Mas a amplitude desses impactos variou em função da incidência de pragas em cada região (BROOKES, 2003).

Como no caso do algodão, a redução nos custos da produção de milho convencional também está diretamente relacionada com a intensidade em que é aplicado inseticida. O estudo de Brookes (2003) comparou os custos das duas principais regiões produtoras de milho na Espanha Sarinena e Barbastro. Na região de Sarinena, onde o uso de inseticidas era intenso, a redução do custo total de produção foi de 23,5\% em média; mas, em alguns casos, chegou a 83,5\%. Já na região de Barbastro, onde o uso de inseticidas era muito reduzido, a adoção do milho Bt causou um aumento de $18,5 \%$ no custo total de produção, porque os custos mais elevados com sementes não foram compensados com a redução dos custos com inseticidas.

Além dos impactos sobre o custo, a utilização do milho Bt está permitindo um maior aproveitamento da safra para a produção de alimento humano e animal. Uma pesquisa recente em 107 unidades produtivas, mostrou que os níveis de fumonisinas (toxinas) encontradas nos grãos de milho Bt foram menores do que nas variedades convencionais. Por isso, a produção de milho Bt aumenta a porcentagem de grãos de milho que podem ser utilizados para consumo humano e rações (HAMMOND et al., 2004).

\section{A Inserção no Mercado}

Para a difusão de um novo produto não bastam custos de produção mais baixos ou rendimentos mais elevados: é necessário, também, que esse produto seja aceito pelo mercado consumidor. No caso dos cultivos GM, a aceitação do mercado está relacionada não apenas com a preferência do consumidor, mas também com as regulamentações existentes nos países compradores.

Os Estados Unidos, como grande produtor e grande exportador de produtos agrícolas, adotam o "princípio da equivalência substancial", que considera o cultivo GM equivalente ao convencional. Já a União Européia, grande importadora de produtos agrícolas, adotou o "princípio da precaução", que considera o cultivo GM diferente do convencional, portanto, a Europa acredita que o cultivo e o consumo de produtos GM podem causar problemas ainda desconhecidos sobre o meio ambiente e a saúde humana e animal. 
Essa divergência entre os países que cultivam produtos GM - sobretudo Estados Unidos e Argentina - e a União Européia tem servido de argumento para os defensores da tese "Brasil livre de transgênicos". Segundo estes, as supostas barreiras aos produtos GM colocadas pela Europa cria um mercado para os produtos convencionais. Assim, o Brasil, livre de transgênicos, poderia ser o grande fornecedor para esses mercados.

Entretanto, a evolução recente do mercado de produtos GM mostra que essa tese não se sustenta. No caso do mercado de soja, por exemplo, a evolução recente não indica nenhuma vantagem da soja convencional em relação à soja GM.

Nos últimos dez anos ocorreram duas modificações na estrutura do mercado mundial de soja: uma, do lado da demanda; e outra, do lado da oferta. Primeiro, houve um aumento significativo de participação da Ásia - sobretudo da China - nas importações mundiais. Pelo lado da oferta, houve um aumento da participação do Brasil nas exportações mundiais.

Entre os críticos da adoção de transgênicos no Brasil, há uma tendência em interpretar esse aumento espetacular das exportações brasileiras como uma sinalização inequívoca de que o mercado consumidor dá preferência à soja tradicional. Entretanto, existem outros dados que dificultam essa interpretação de que a "preferência por soja convencional" explica isoladamente o aumento das exportações brasileiras. Há outras variáveis que devem ser consideradas, dentre as quais destacam-se:

- o desempenho comercial da Argentina;

- o aumento dos custos de produção da soja nos EUA;

- as mudanças na estrutura da demanda mundial;

- o desempenho comercial do Rio Grande do Sul;

- a evolução do preço da soja convencional.

As Tabelas 5 e 6 mostram a evolução das exportações mundiais de soja entre 1993 e 2002. O que se observa é uma mudança significativa nesse período, com uma queda da participação dos Estados Unidos e um aumento da participação do Brasil e da Argentina. Mesmo com um aumento absoluto de cerca de oito milhões de toneladas, as exportações dos Estados Unidos caíram de $75 \%$ da exportação mundial, em 1993, para 55\%, em 2002.

Essa queda de market-share da soja dos Estados Unidos foi resultado de dois problemas: queda na produtividade e aumento dos custos (WILKINSON, 2002; PEREIRA, 2004). E esses dois problemas não estão relacionados com o uso da soja GM.
O aumento dos custos de produção não está relacionado com o aumento dos custos de sementes, mas sim com o aumento dos custos fixos - principalmente o custo da terra. Os custos fixos nos Estados Unidos, em 2000, eram 75\% maiores do que no Brasil e 50\% maiores do que na Argentina (WILKINSON, 2002).

Já a queda na produtividade é devida a eventos climáticos e não ao uso da semente GM. Só em 2003, os Estados Unidos perderam cerca de 13 milhões de toneladas de soja em relação a sua estimativa inicial, que era de 80 milhões de toneladas (PEREIRA, 2004).

Do mesmo modo, o aumento da produtividade no Brasil também não está relacionado com a baixa taxa de adoção de soja GM, porque esse aumento na produção nacional é devido principalmente ao aumento da produtividade no Rio Grande do Sul, estado com maior taxa de adoção de soja GM no Brasil (PEREIRA, 2004).

Quanto à suposta dificuldade de exportar a soja GM, os dados das Tabelas 5 e 6 mostram que não foi somente o Brasil que aumentou sua participação, mas também a Argentina - que tem uma taxa de adoção de soja GM de quase $100 \%$ (TRIGO et al., 2003). Esse aumento das exporta-

TABELA 5

Evolução das Exportações de Soja em Grão dos Três Maiores Produtores Mundiais

Estados Unidos, Brasil e Argentina - 1993-02

\begin{tabular}{lcccc}
\hline Ano & Total & Estados Unidos & Brasil & Argentina \\
\hline 1993 & 27.761 & 19.511 & 4.190 & 2.428 \\
1994 & 31.849 & 18.126 & 5.367 & 2.942 \\
1995 & 31.624 & 22.992 & 3.493 & 2.526 \\
1996 & 36.684 & 25.960 & 3.647 & 2.056 \\
1997 & 39.669 & 26.375 & 8.340 & 490 \\
1998 & 38.004 & 20.701 & 9.287 & 2.864 \\
1999 & 45.517 & 24.090 & 8.917 & 3.065 \\
2000 & 53.799 & 27.192 & 11.517 & 4.123 \\
2001 & 53.594 & 28.934 & 15.675 & 7.211 \\
2002 & 62.074 & 27.433 & 15.970 & 6.112 \\
\hline
\end{tabular}

Fonte: FNP (2004).

TABELA 6

Evolução do Market-Share dos Três Maiores Exportadores Mundiais de Soja em Grão

Estados Unidos, Brasil e Argentina - 1993-2002

\begin{tabular}{lccc}
\hline Ano & EUA & Brasil & Argentina \\
\hline 1993 & 0,75 & 0,16 & 0,09 \\
1996 & 0,82 & 0,12 & 0,06 \\
2002 & 0,55 & 0,32 & 0,12 \\
\hline
\end{tabular}

Fonte: FNP (2004). 
ções da Argentina não corrobora a tese de que a adoção de cultivos GM implica em perda de competitividade externa.

Além da exportação de soja em grãos, a Argentina apresentou excelente desempenho na exportação de derivados da soja. Ela é atualmente a maior exportadora de farelo de soja do mundo - posição que era ocupada pelo Brasil até 1997. A Tabela 7 mostra que, entre 1996 e 2003, enquanto a exportação de farelo de soja do Brasil aumentou de oito para 14 milhões de toneladas, a da Argentina aumentou de oito para 18 milhões de toneladas. Em 2003, a Argentina respondeu por $41,3 \%$ das exportações mundiais de farelo e por $48 \%$ das de óleo de soja (FNP, 2004).

Assim, os estudos mostram que a adoção de transgênicos na Argentina, ao invés de prejudicá-la comercialmente, garantiu sua maior participação no mercado mundial no decorrer da década de 90. A Argentina tem um sério problema de escassez de terra. No entanto, a adoção de transgênicos contribuiu para o aumento da produtividade e para o aumento da área de plantação direta - o que per- mitiu o aumento da produção de soja sem prejuízos para a produção de outras culturas importantes para sua economia, como o milho e o trigo (TRIGO et al., 2003).

No caso do Brasil, as exportações do Rio Grande do Sul não foram prejudicadas pela introdução da soja GM. O Rio Grande do Sul é o terceiro maior produtor de soja do Brasil. Em 2003, sua produção foi de 9,8 milhões de toneladas, cifra superada apenas pelo Mato Grosso, com 15,2 milhões de toneladas, e pelo Paraná, com 11,2 milhões de toneladas (FNP, 2004). É o estado brasileiro com maior taxa de adoção de soja transgênica. Pelo Gráfico 4, observa-se que a participação desse estado na exportação brasileira de soja aumentou de 5\%, em 1996, para 20\%, em 2003.

Além do aumento das exportações do Rio Grande do Sul, não foi observada nenhuma tendência de diferenciação entre o preço da soja desse estado do das demais regiões do país, como mostra o Gráfico 5. A comparação entre o preço da soja exportada do Rio Grande do Sul e o preço médio dos demais estados não corrobora a tese de que

TABELA 7

Exportação de Farelo de Soja, segundo Principais Produtores Mundiais Estados Unidos, Brasil e Argentina - 1996-03

\begin{tabular}{|c|c|c|c|c|c|c|c|c|}
\hline \multicolumn{9}{|c|}{ Em milhões de toneladas } \\
\hline Produtores Mundiais & 1996 & 1997 & 1998 & 1999 & 2000 & 2001 & 2002 & 2003 \\
\hline$\overline{E U A}$ & 6 & 8 & 6 & 7 & 7 & 7 & 6 & 5 \\
\hline Argentina & 8 & 8 & 12 & 14 & 14 & 15 & 17 & 18 \\
\hline Brasil & 11 & 10 & 10 & 10 & 9 & 11 & 13 & 14 \\
\hline
\end{tabular}

Fonte: FNP (2004).

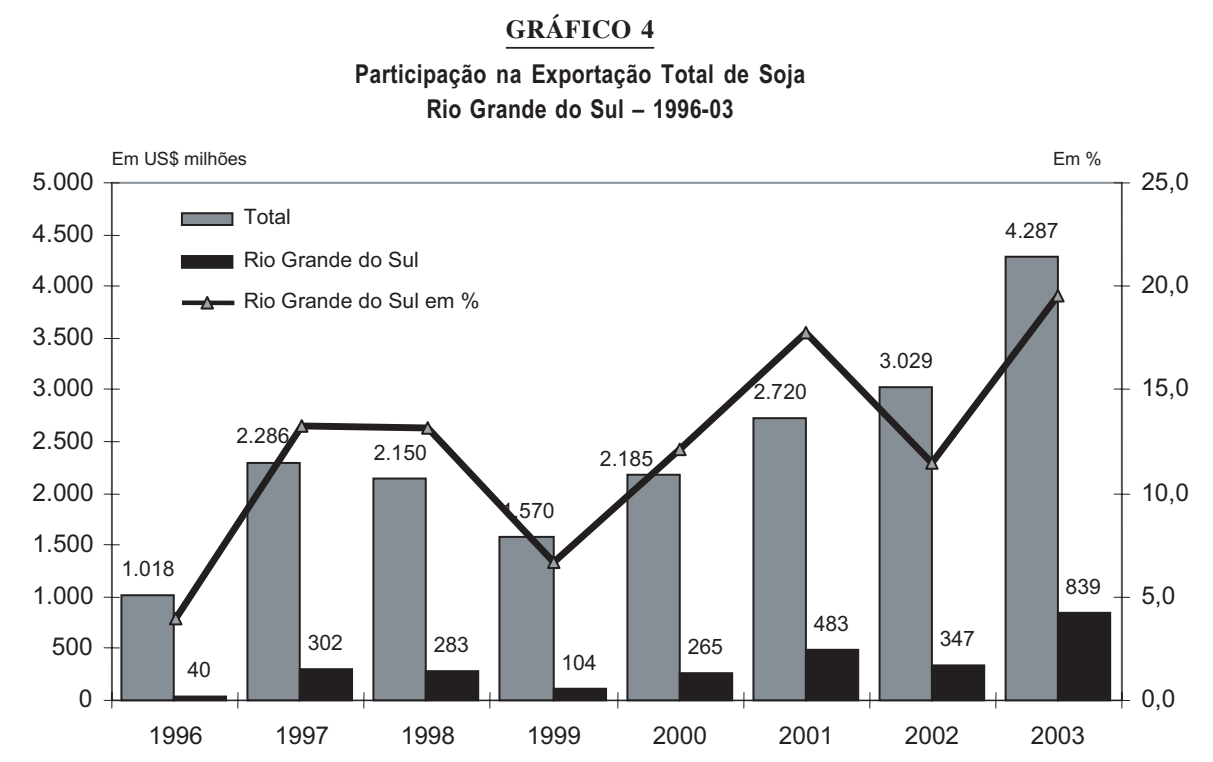

Fonte: Ministério do Desenvolvimento, Indústria e Comércio Exterior / Secretaria de Comércio Exterior - Secex. Elaboração dos autores. 
existe um preço diferenciado para a soja convencional, pois os preços são praticamente os mesmos.

Se, do lado da oferta, a grande mudança na década passada no mercado mundial de soja foi o aumento da participação da América Latina - especialmente Argentina e Brasil - do lado da demanda a grande novidade foi o aumento da participação da Ásia na importação mundial. Sua participação passou de 30\%, em 1996/97, para 72\%, em 2003/04. Grande parte desse aumento da demanda asiática foi resultado do aumento da demanda da China, que em 2003/04 representou 29\% da importação mundial: a mesma participação da União Européia (Tabela 8).

A expansão do mercado asiático pode reduzir os possíveis ganhos com a soja tradicional, uma vez que os principais compradores da região - Japão e China - têm mostrado indiferença quanto à escolha entre a soja convencional e a GM. O Japão continua importando quase $100 \%$ dos Estados Unidos; e a China, em 2002, comprou praticamente o mesmo tanto dos Estados Unidos e do Brasil (PEREIRA, 2004).

Em termos absolutos, o Brasil aumentou suas exportações tanto para a União Européia quanto para a Ásia. Porém, em termos relativos, a participação desta última aumentou de $12 \%$ para $38 \%$, entre 1996 e 2003, enquanto que a participação da Europa caiu de $82 \%$ para $53 \%$ (Gráfico 6).

Dada a indiferença dos países asiáticos em relação ao tipo da soja, quanto maior a participação deles no mercado comprador, menor será a possibilidade de o Brasil conseguir

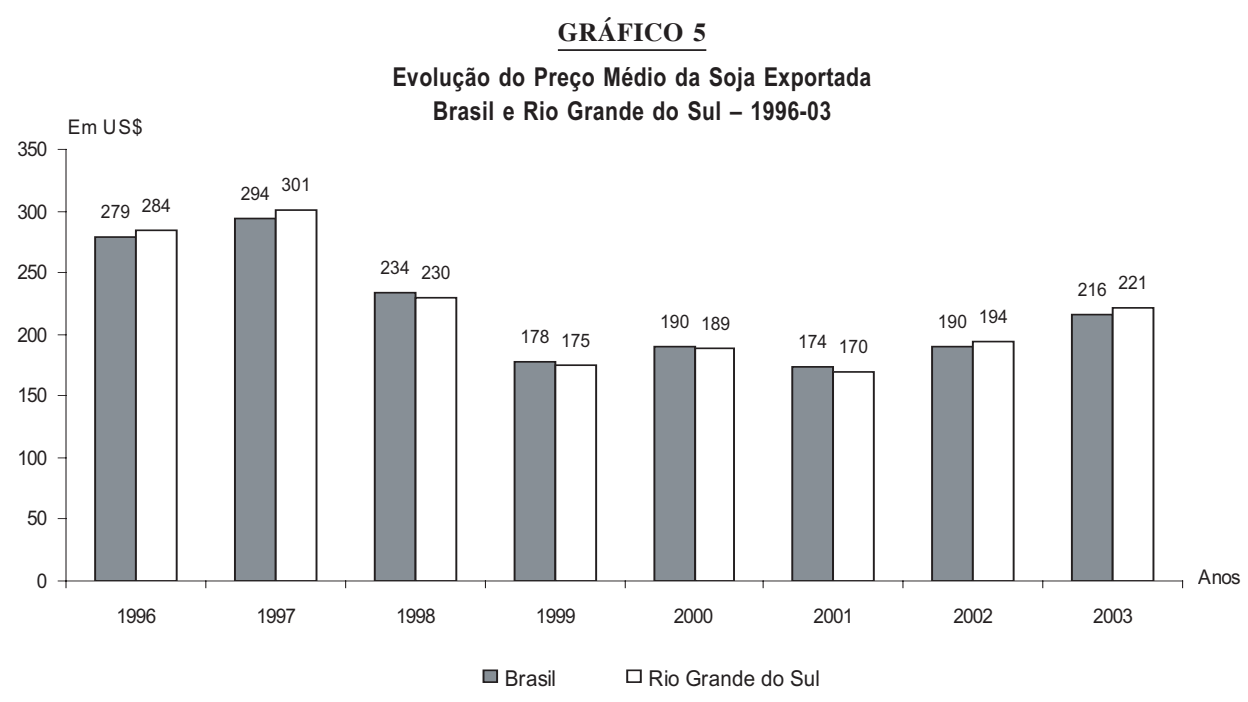

Fonte: Ministério do Desenvolvimento, Indústria e Comércio Exterior / Secretaria de Comércio Exterior - Secex. Elaboração dos autores.

TABELA 8

Importação Mundial de Soja, segundo Regiões 1996-2004

\begin{tabular}{|c|c|c|c|c|}
\hline \multirow{2}{*}{ Regiões } & \multirow{2}{*}{$\begin{array}{c}1996 / 97 \\
\text { (Em mil ton. métricas) }\end{array}$} & \multirow{2}{*}{$\begin{array}{c}2003 / 04 \\
\text { (Em mil ton. métricas) }\end{array}$} & \multicolumn{2}{|c|}{ Participação (\%) } \\
\hline & & & $1996 / 97$ & $2003 / 04$ \\
\hline Total & 35.412 & 64.102 & 100,0 & 100,0 \\
\hline União Européia & 14.572 & 18.296 & 41,0 & 29,0 \\
\hline China & 2.274 & 18.500 & 6,0 & 29,0 \\
\hline Japão & 5.043 & 5.050 & 14,0 & 8,0 \\
\hline Taiwan & 2.632 & 2.260 & 7,0 & 4,0 \\
\hline Tailândia & 550 & 1.800 & 2,0 & 3,0 \\
\hline Sub-Total Ásia & 10.499 & 27.610 & 30,0 & 43,0 \\
\hline México & 2.720 & 5.000 & 8,0 & 8,0 \\
\hline Outras & 7.621 & 13.196 & 22,0 & 21,0 \\
\hline
\end{tabular}

Fonte: FNP (2004). 


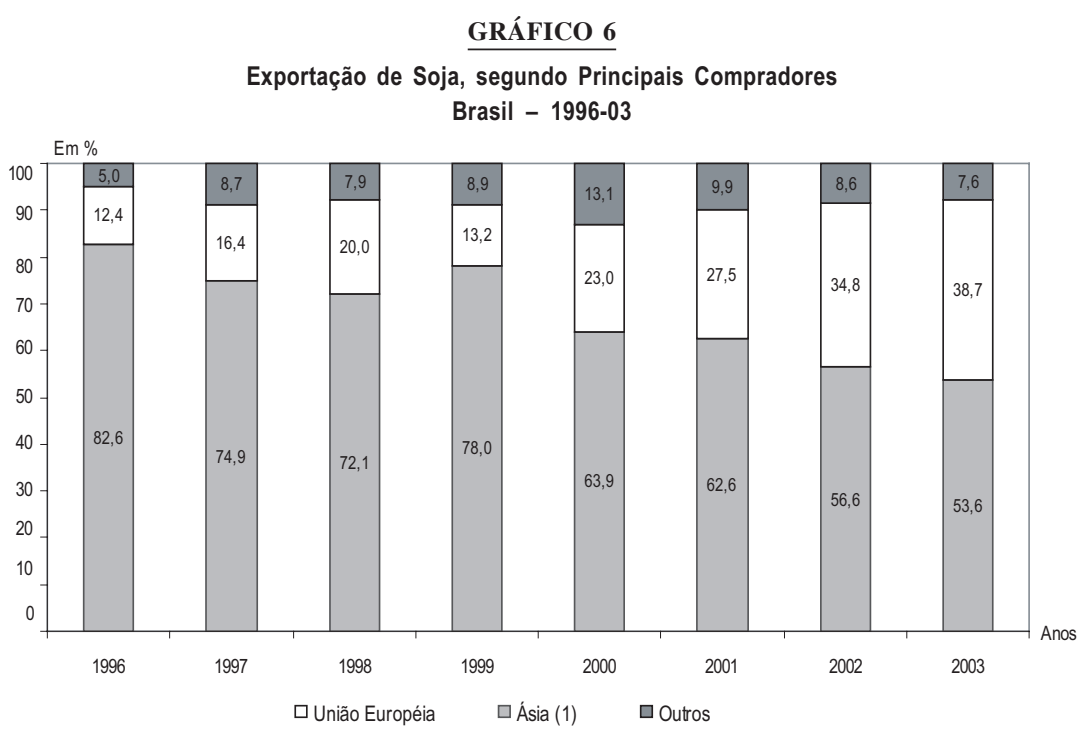

Fonte: Ministério do Desenvolvimento, Indústria e Comércio Exterior / Secretaria de Comércio Exterior - Secex. Elaboração dos autores. (1) Exclui o Oriente Médio.

um preço melhor para a soja convencional. Além do mais, com a redução de custos da soja transgênica, o aumento da competitividade da Argentina e de outros países poderá resultar na perda de participação da soja brasileira no mercado mundial. Se a Ásia continuar aumentando sua participação no mercado mundial, tudo indica que a competitividade terá como base a variável "preço".

\section{CONSIDERAÇÕES FINAIS}

Este trabalho objetivou analisar a evolução e os impactos econômicos da difusão dos cultivos geneticamente modificados na agricultura. As principais conclusões foram: - a difusão dos cultivos geneticamente modificados está relacionada a ganhos econômicos para os produtores agrícolas, como: redução de custos, aumento da produtividade e aumento da eficiência na administração do controle de pragas;

- os impactos positivos dos cultivos GM dependem das especificidades de cada região. No caso dos cultivos resistentes a insetos, os ganhos dependerão da incidência de pragas. A redução nos gastos com inseticidas deverá ser grande o suficiente para compensar o aumento do custo com sementes;

- apesar das divergências internacionais quanto à forma de regular a pesquisa, a produção e o comércio dos cultivos GM, não há nenhuma evidência empírica de que esses cultivos têm baixa competitividade em comparação com os cultivos convencionais. A Argentina, o país com a maior taxa de adoção de soja transgênica, conseguiu aumentar significativamente sua exportação de soja em grãos e derivados. Nos últimos dez anos houve um grande aumento da participação da Ásia no mercado consumidor de soja e esta, ao contrário da União Européia, não apresenta restrições ao comércio de cultivos GM. E por fim, não há evidências empíricas que comprovem a tese de que os produtos convencionais têm a preferência do mercado, e, portanto, apresentam um preço maior do que os geneticamente modificados.

\section{NOTAS}

1. A concentração geográfica dos cultivos GM comercializados reflete, em grande medida, a geografia anterior à sua introdução, já que no momento inicial eles substituem cultivares não geneticamente modificados.

2. A rede de estudos genômicos criada pelo Ministério da Ciência e Tecnologia e pela Fapesp inclui diversos estudos relacionados à saúde humana: o genoma humano do câncer, genoma do parasita Schistosoma mansoni e o seqüenciamento do genoma do parasita Leptospira interrogans, entre outros.

\section{REFERÊNCIAS BIBLIOGRÁFICAS}

BORÉM, A.; SANTOS, F.R. Biotecnologia Simplificada. Viçosa: Ed. UFV, 2001. 
BROOKES, G. The farm level impact of using Bt maize in Spain. In: INTERNATIONAL CONFERENCE ON PUBLIC GOODS AND PUBLIC POLICY FOR AGRICULTURAL BIOTECHNOLOGY, 7., International Consortium on Agricultural Biotechnology Research (ICABR). Ravello (Italy), June 29 - July 32003.

BONNY, S. Success factors, issues and prospects for the first GM crops: the case of Roundup Ready ${ }^{\circledR}$ soybean in the USA. In: INTERNATIONAL CONFERENCE ON PUBLIC GOODS AND PUBLIC POLICY FOR AGRICULTURAL BIOTECHNOLOGY, 7., International Consortium on Agricultural Biotechnology Research (ICABR). Ravello (Italy), June 29 - July 32003.

CIB - CONSELHO DE INFORMAÇÕES SOBRE BIOTECNOLOGIA. Newsletters, Ano 4, n. 34, set. 2004.

\section{CARPENTER, J.E., GIANESSI, L.P. Agricultural}

biotechnology: updated benefit estimates. Washington, DC: National Center for Food and Agricultural Policy, 2001. p. 148 .

DAL POZ, M.E. et al. Direitos de propriedade intelectual em biotecnologia: um processo de construção. In: SILVEIRA, J.M.F.J. et al. (Org.). Biotecnologia e recursos genéticos: desafios e oportunidades para o Brasil. Campinas: Instituto de Economia/Finep, 2004

DEMONT, M. et al. Impact of new technologies on agricultural production systems: The cases of agricultural biotechnology and automatic milking. In: BOUQUIAUX, J.-M.; LAUWERS, L.; VIAENE, J. (Ed.). New Technologies and Sustaintability. Brussels: CLE-CEA, 2001. p. 11-38.

DUFFY, D. Who benefits from biotechnology? Paper apresentado na American Seed Trade Association Meeting, Chicago, 5-7 dez. 2001

ELBEHRI, A.; MACDONALD, S. Estimating the Impact of Transgenic Bt Cotton on West and Central Africa: A General Equilibrium Approach. World Development, forthcoming, 2005.

EMBRAPA. Nota Informativa: Pesquisa Biotecnológica na Embrapa, 2004. Disponível em:

<http://www.cenargen.embrapa.br/>.

FAO - FOOD AND AGRICULTURE ORGANIZATION OF THE UNITED NATIONS. The State Of Food and Agriculture 2003-2004 - Agricultural Biotechnology: Meeting the needs of the poor? Disponível em: <http://www.fao.org/documents>.

$$
\text { Key Statistics of Food and Agriculture External }
$$

Trade. Disponível em:

<http://www.fao.org/countryprofiles/inventory.asp?lang=es >.

FNP CONSULTORIA. Agrianual, 2004. Disponível em: <http://www.fnp.com.br/prodserv/estatisticas/>

FONSECA, M.G.D. et al. Biotecnologia vegetal e produtos afins: sementes, mudas e inculantes. In: SILVEIRA, J.M.F.J. et al. (Org.). Biotecnologia e Recursos Genéticos: desafios e oportunidades para o Brasil. Campinas: Instituto de Economia/Finep, 2004

GIANESSI, L.P. et al. Plant Biotechnology: Current and Potential Impact for Improving Pest Management in US Agriculture. An Analysis of 40 Case Studies. Washington, DC: National Center for Food and Agricultural Policy, 2002.

HAMMOND, B.G. et al. Lower fumonisin mycotoxin levels in the grain of Bt corn grown in the United States in 2000-2002. Journal of Agriculture and Food Chemistry, n. 52, p. 1.390$1.397,2004$

HUANG, J. et al. Biotechnology as an alternative to chemical pesticides: a case study of Bt cotton in China. Agricultural Economics, n. 29, p. 55-67, 2003.
HUBBELL, B.J.; WELSH, R. Transgenic crops: Engineering a more sustainable agriculture? Agriculture and Human Values, n. 15, p. $43-56,1998$.

JAMES, C. Preview: Global Status of Commercialized Transgenic Crops: 2004. ISAAA Briefs, ISAAA: Ithaca, NY, n. 30. 2004. Disponível em: 〈http://www.isaaa.org>.

Preview: Global Status of Commercialized Transgenic Crops: (vários anos). ISAAA Briefs, ISAAA: Ithaca, NY, vários números. Disponível em: <http://www.isaaa.org >.

JUDICE, V.M.M. Biotecnologia e Bioindústria no Brasil: Evolução e Modelos Empresariais. In: SILVEIRA, J.M.F.J. et al. (Org.). Biotecnologia e recursos genéticos: desafios e oportunidades para o Brasil. Campinas: Instituto de Economia/Finep, 2004.

MARRA, M.C.; PARDEY, P.G.; ALSTON, J.M. The payoffs to transgenic field crops: an assessment of the evidence. AgBioForum, v. 5, n. 2, 2002.

MOSCHINI, G. et al. Roundup Ready soybeans and welfare effects in the soybean complex. Agribusiness, n. 16, p. 33-55, 2002 .

QAIM, M.; TRAXLER, G. Roundup Ready soybeans in Argentina: farm level and aggregate welfare effects. Agricultural Economics, 2004.

PEREIRA, S.R. A evolução do complexo soja e a questão da transgenia. Revista de Política Agrícola, Ano XIII, n. 2, abr./ maio/jun. de 2004.

SALLES FILHO, S.L.M (Coord.). et al. Ciência, Tecnologia e Inovação: a reorganização da pesquisa pública no Brasil. 1. ed. Campinas: Ed. Komedi/Capes, 2000. 413p.

TRAXLER, G. Challenges Facing Plant Biotechnology in Latin America. Presentation at the Inter-American Development Bank, Washington, DC: Nov. 7, 2000.

TRIGO, E. et al. Los transgenicos en la agricultura argentina. In: Global Biotechnology Forum - Bioindustries in Development, Brasília, p. 22-25, jul. 2003.

VALOIS, A.C.C. Importância dos transgênicos para a agricultura. Cadernos de Ciência e Tecnologia, Brasília, v. 18, n. 1, p. 27-53, jan./abr. 2001.

WILKINSON, J. Biotecnologia e agronegócios. Campinas: Unicamp/IE/NEIT, dez. 2002.

José Maria Ferreira Jardim da Silveira: Engenheiro Agrônomo, Doutor em Economia, Professor Assistente Doutor do Instituto de Economia da Unicamp. Coordenador do Núcleo de Estudos Agrícolas do IE/Unicamp e Pesquisador do Geopi/IG-Unicamp. Conselheiro do Conselho de Informação em Biotecnologia (jmsilv@eco.unicamp.br).

Izaias de Carvalho Borges: Economista, Mestre em Economia pelo Instituto de Economia da Unicamp e Pesquisador do NEA/IE-Unicamp (icborges@eco.unicamp.br).

Antonio Márcio Buainain: Economista e Advogado, Doutor em Economia, Professor Assistente Doutor do Instituto de Economia da Unicamp. Pesquisador do NEA e do Geopi (buainain@eco.unicamp.br).

Artigo recebido em 1 de junho de 2005. Aprovado em 30 de junho de 2005. 